\title{
Comparison of intramuscular glucagon and intravenous dextrose in the treatment of hypoglycaemic coma in an accident and emergency department
}

\author{
A. W. PATRICK ${ }^{1}$, A. COLLIER ${ }^{1}$, D. A. HEPBURN ${ }^{1}$, \\ D. J. STEEDMAN ${ }^{2}$, B. F. CLARKE ${ }^{1}$ \& C. ROBERTSON ${ }^{2}$ \\ ${ }^{1}$ Diabetic Department and ${ }^{2}$ Accident and Emergency Department, Royal Infirmary, \\ Edinburgh
}

\section{SUMMARY}

Hypoglycaemia remains a serious and much feared complication of insulin therapy. In this study, patients attending an accident and emergency department in hypoglycaemic coma were randomized to treatment with either intravenous dextrose $(25 \mathrm{~g})$ or intramuscular glucagon $(1 \mathrm{mg})$, administered into the right thigh. Restoration of normal conscious level was slower after glucagon than dextrose $(9.0$ vs $3.0 \mathrm{~min}, P<0.01)$, although the average duration of hypoglycaemic coma was $120 \mathrm{~min}$. Two patients in the glucagon-treated group, who failed to show satisfactory recovery after $15 \mathrm{~min}$, required additional treatment with intravenous dextrose. On questioning following recovery, all except two patients reported loss of awareness of the onset of hypoglycaemia.

Intramuscular glucagon is valuable in the treatment of severe hypoglycaemia outwith hospital and, although the slightly slower and less predictable recovery may appear to make it a less attractive option than intravenous dextrose in the accident and emergency department, this must be balanced against the advantages of ease of administration and a lower incidence of serious adverse effects.

\section{INTRODUCTION}

Hypoglycaemia remains a significant cause of mortality in diabetics (Tunbridge, 1981) and up to $13 \%$ of patients treated with insulin will experience at least one severe hypoglycaemic episode each year (Potter et al., 1982; Casparie \& Elving, 1985;

Correspondence: $\operatorname{Dr}$ A. W. Patrick, Registrar, Diabetic Department, Royal Infirmary, Edinburgh EH3 9 YW, Scotland. 
Matthews et al., 1986). Intravenous dextrose continues to be widely used by medica就 staff to treat hypoglycaemia but intravenous glucagon has been shown to be an effective्్ర alternative (Collier et al., 1987), with a low risk of intravenous thrombosis of extravascular complications (Shipp et al., 1964; Collier et al., 1987). To date, however other routes of administration of glucagon have not been compared with intravenous. dextrose, although glucagon, administered intramuscularly or subcutaneously, is increasingly used by families and friends of diabetic patients to treat severe hypogly? caemia at home or work.

\section{METHODS}

The study group consisted of 29 insulin-treated diabetic patients, presenting consecu蹧 tively to the Accident and Emergency Department, Royal Infirmary, Edinburgh $\frac{\text { }}{5}$. Scotland with hypoglycaemic coma. Hypoglycaemia was confirmed on a capillary blood specimen using a Reflolux II Meter (Boeringer Mannheim Mannheim, FRG) and patients were randomly allocated to treatment with either $50 \mathrm{mg}$ $50 \%$ dextrose intravenously or $1 \mathrm{mg}$ glucagon intramuscularly, administered into a defined site in the right thigh. Venous blood was withdrawn prior to treatment for measurement of plasma glucose, alcohol and glycated haemoglobin, with furthef samples being taken after 5, 10, 15 and $30 \mathrm{~min}$ for plasma glucose estimation. Time्ध taken to recover normal conscious level was noted and a further $12.5 \mathrm{~g}$ of dextrose vras given intravenously if satisfactory clinical recovery had not occurred $15 \mathrm{~min}$ af treatment. Following recovery, patients, and any relatives or friends present, we questioned to determine the duration of hypoglycaemia prior to treatment, although ing several cases it was only possible to obtain a rough estimate of this. Details wer obtained of insulin and other drug therapy, in addition to possible precipitating cause or any preceding loss of awareness of the onset of hypoglycaemia.

Students T-tests or Wilcoxon ranked sum tests were used, as appropriate, to compare the two treatment groups. The study protocol was approved by the local Hospital Advisory Ethical Committee.

\section{RESULTS}

The glucagon- $(n=15)$ and dextrose-treated $(n=14)$ groups were not significantly different in terms of age, duration of diabetes, initial plasma glucose, glycated. haemoglobin or estimated duration of coma (Table 1). Glycaemic profiles following treatment with dextrose and glucagon were however significantly different (Fig. 1) an \$애 the glucagon-treated group was slower to achieve normal conscious level (9 (5-30) min than the dextrose-treated group $(3(2-15) \mathrm{min}) ; P<0.01$. Two of the glucagon-treated group, but none of the patients who received dextrose, required administration of additional intravenous dextrose on account of failure to show signs of clinical recovery? within $15 \mathrm{~min}$ of treatment. There was no correlation between the time taken to recover్ 
Table 1 Patient data for glucagon- and dextrose-treated groups.

\begin{tabular}{|c|c|c|}
\hline & $\begin{array}{l}\text { Glucagon-treated } \\
\text { group }(n=15)\end{array}$ & $\begin{array}{l}\text { Dextrose-treated } \\
\text { group }(n=14)\end{array}$ \\
\hline Sex & $12 \mathrm{M}: 3 \mathrm{~F}$ & $10 \mathrm{M}: 4 \mathrm{~F}$ \\
\hline Age (yr) & $47(17)$ & $48(17)$ \\
\hline Duration of diabetes $(\mathrm{yr})$ & $19(2-33)$ & $20(3-31)$ \\
\hline Initial plasma glucose $\left(\mathrm{mmol} \mathrm{l}^{-1}\right)$ & $1.3(0.5)$ & $1.2(0.5)$ \\
\hline Glycated haemoglobin (\%) & $9.7(1.9)$ & $9 \cdot 6(1 \cdot 7)$ \\
\hline Duration of coma (min) & $120(60-240)$ & $120(20-480)$ \\
\hline
\end{tabular}

Mean (SD) or median (range) as appropriate.

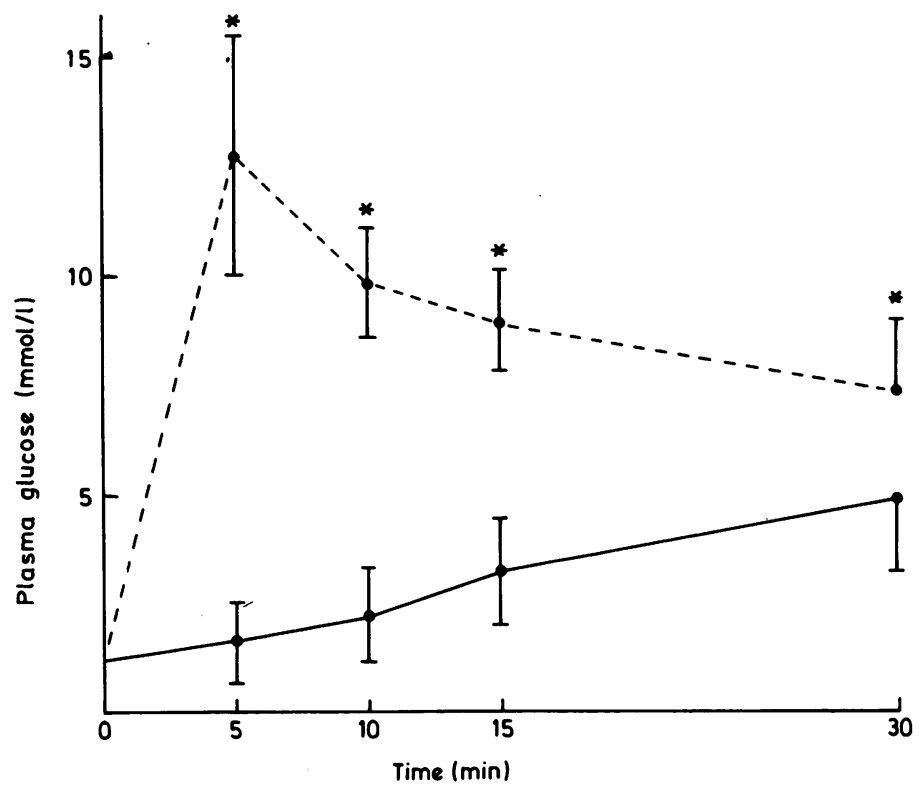

Fig. 1 Glycaemic profiles after glucagon (solid line) and dextrose (dotted line) expressed as means (SD). Significant differences between two values are indicated by *.

consciousness and either the initial plasma glucose concentration or the duration of hypoglycaemia.

A clear precipitating cause for the episode of hypoglycaemia was often not apparent and, in particular, alcohol was only detected in the plasma of three patients, with the highest level recorded being $3 \mathrm{mmol} \mathrm{1}^{-1}$. Nineteen patients were on treatment with a twice daily mixture of soluble, and isophane or lente insulins. The remaining 10 patients were receiving once daily lente or protamine zinc insulins, either with or without additional soluble insulin before breakfast. All except one patient in each group reported either partial or total loss of awareness of the onset of hypoglycaemia, but none were receiving treatment with beta blockers or other drugs which might alter hypoglycaemic awareness or affect the counterregulatory response. 
Our results confirm the findings of others (Elrick et al., 1958; Shipp et al., 1964; Amap \& Wranne, 1988), in demonstating that intramuscular glucagon is effective in restoring the plasma glucose level towards normal, even following prolonged hypoglycaemie. coma, as was the case in many of the patients reported in the present study. The rate of recovery was, however, slower than that reported following intravenous glucagon in क similar study in an accident and emergency department (Collier et al., 1987) and this finding might be expected on the basis of previous research into the pharmacokinetics of glucagon, with higher plasma levels being obtained during the first $15 \mathrm{~min}$ afte尺 intravenous glucagon in comparison with either intramuscular or subcutaneous admini stration (Muhlhauser et al., 1985). In the present study, the difference between the median recovery times of the groups treated with intravenous dextrose and glucagon ( 6 min), although statistically significant, was however small in comparison with the average duration of hypoglycaemic coma $(120 \mathrm{~min})$. It is probably of more importance्ष that two patients in the glucagon-treated group required additional therapy with intravenous dextrose. These patients could not have been predicted in advance on the basis of the initial plasma glucose level or duration of coma, and nor was there an $\omega_{6}^{\omega}$ evidence of preceding alcohol intake or hepatic disease, which might have affected the clinical response to glucagon.

When questioned following recovery, it was striking that all except two of the patient in the study reported at least partial loss of hypoglycaemic awareness. It has previouslye been shown that patients with glycated haemoglobin levels closer to the non-diabetie range are at greater risk of hypoglycaemia (Matthews et al., 1986; Collier et al., 198\$) and tight glycaemic control, as present in several of our patients, is known to associated with reduced awareness of the onset of hypoglycaemia, in addition ton impaired glucose counterregulatory responses (Amiel et al., 1987). It is likely, however that the long average duration of diabetes $(20 \mathrm{yrs})$ is also a significant factor in? explaining the loss of awareness in many of the group reported here.

Although the rather slower and less predictable recovery rate following intramuscular: glucagon may appear to make this a less attractive alternative to intravenous dextrose in the treatment of severe hypoglycaemia in the specific setting of the accident ando emergency department, this has to be weighed up against the advantages of ease of administration and absence of the intravenous and extravascular complications associated with the use of concentrated dextrose solutions.

\section{REFERENCES}

Aman J. \& Wranne L. (1988) Hypoglycaemia in childhood diabetes II. Effect of subcutaneous o intramuscular injection of different doses of insulin. Acta Paediatrica Scandinavia 77, 548-53.

Amiel S. A., Tamborlane W. V., Simonson D. C. \& Sherwin R. S. (1987) Defective glucose counterregulation after strict glycemic control of the insulin-dependent diabetes mellitus. New England fournal of Medicin£ 316, $1376-83$.

Casparie A. F. \& Elving L. D. (1985) Severe hypoglycemia in diabetic patients: frequency, causes prevention. Diabetes Care 8, 141-5.

Collier A., Steedman D. J., Patrick A. W., Nimmo G. R., Matthews D. M., Macintyre C. C. A., Little K. \&@ Clarke B. F. (1987) Comparison of intravenous glucagon and dextrose in treatment of severe hypogly $\square$ caemia in an accident and emergency department. Diabetes Care 10, 712-751. 
Elrick H, Witten T. A. \& Arai Y. (1958) Glucagon treatment of insulin reactions. New England fournal of Medicine 258, 476-80.

Matthews D. M., Patrick A. W., Collier A., Kellett H. A., Macintyre C. C. A., Steel J. M. \& Clarke B. F. (1986) Awareness and use of glucagon amongst insulin treated diabetics. British Medical fournal 293, 3678.

Muhlhauser I., Koch J. \& Berger M. (1985) Pharmacokinetics and bioavailability of injected glucagon: differences between intramuscular, subcutaneous and intravenous administration. Diabetes Care 8, 39-42.

Potter J., Clarke P., Gale E. A. M., Dave S. H. \& Tattersall R. B. (1982) Insulin induced hypoglycaemia in an accident and emergency department: the tip of the iceberg. British Medical fournal 285, 1180-2.

Shipp J. C., Delcher H. K. \& Munroe J. F. (1964) Treatment of insulin hypoglycaemia in diabetic campers: a comparison of glucagon (1 and $2 \mathrm{mg}$ ) and glucose. Diabetes 13, 645-8.

Tunbridge W. M. G. (1981) Factors contributing to deaths of diabetics under 50 years. Lancet ii, 569-72. 